\title{
Werken met protocollaire behandelingen
}

\author{
G.P.J. Keijsers, M. Verbraak, E. Ten Broeke en K. Korrelboom
}

\begin{abstract}
Samenvatting
In deze bijdrage ${ }^{1}$ wordt stilgestaan bij een verantwoord gebruik van psychologische, protocollaire Empirically Established Treatments (ESTs). Het aantal psychische stoornissen waarvoor ESTs beschikbaar komen neemt nog steeds toe. Tegelijkertijd blijkt het voor een aantal andere stoornissen alsmaar niet mogelijk om duidelijk 'betere' behandelingen te ontwikkelen en blijft traditionele, individuspecifieke psychologische behandeling gewenst en nodig. De geclassificeerde stoornis biedt vooralsnog onvoldoende aanknopingspunten voor een gestandaardiseerde aanpak. Wanneer bij patiënten wel een geïndiceerde EST beschikbaar is moet de patiënt daarvan op de hoogte worden gesteld en moet de EST ook aangeboden kunnen worden. Opleidingen behoren ESTs te onderwijzen.
\end{abstract}

Trefwoorden: ESTs - opleiding - protocol - psychologische behandeling

Van circa veertig veelvoorkomende psychische stoornissen bij volwassenen zijn de effecten van een bepaalde, psychologische behandeling met stelligheid aangetoond. Dat wil zeggen dat in meerdere gerandomiseerde, gecontroleerde studies gevonden werd dat deze behandeling effectiever is dan een andere psychologische, medicamenteuze of placebobehandeling. Deze behandelingen worden vaak aangeduid met 'Empirically Established Treatments', ofwel ESTs. Voor de circa veertig stoornissen werden 108 psychologische ESTs vastgesteld, meestal dus meerdere behandelingen per stoornis. De stoornissen waarvoor ESTs werden vastgesteld zijn alle angststoornissen, unipolaire en bipolaire depressie, eetstoornissen, obesitas, schizofrenie, relatieproblemen, orgasmestoornissen, parafilia, hoofdpijn en andere pijnstoornissen, alcoholen cocaïnemisbruik, nicotine- en opiatenafhankelijkheid, dismorfofobie, ongewenste gewoonten en afhankelijke en borderline persoonlijkheidsstoornis (o.a. Barlow e.a. 1999; Chambless \& Ollendick 2001; DeRubeis \& Crits-Christoph 1998; Keijsers e.a. 2004; Roth \& Fonagy 2005). De ESTs worden uitgevoerd met behulp van een handleiding of protocol en zijn in praktisch alle gevallen specifiek gericht op de desbetreffende stoornis. Deze protocollaire, stoornisspecifieke ESTs zijn de krachtigste psychologische behandelingen die tot nu toe binnen klinische psychologie en psychiatrie ontwikkeld werden. De prepost-effect sizes liggen tussen 1 en 3 . Dit is ruim boven de effect size van 0,85 dat vanaf de eerste grote metastudies uit de jaren ' 80 van de vorige eeuw gold als het algemene psychotherapie-effect (zie o.a. Keijsers e.a. 2004). Wanneer patiënten voldoen aan de diagnostische criteria van de genoemde stoornissen worden deze protocollaire ESTs door velen dan ook als de behandelingen van voorkeur beschouwd (o.a. Barlow e.a. 2007).

Dat inmiddels voor zo'n 40 veel voorkomende psychische stoornissen ESTs ontwikkeld zijn, wil beslist niet zeggen dat alle DSM-diagnoses zich uiteindelijk gaan lenen voor een gestandaardiseerde behandeling. Dat is zelfs niet erg aannemelijk. Er worden weliswaar steeds nieuwe behandelingen en behandeltoepassingen ontwikkeld en het aantal stoornissen waarvoor superieure behandeleffecten worden gevonden bij toepassing van een bepaalde behandeling neemt nog steeds toe. Maar daar staat tegenover dat voor een aantal stoornissen dergelijke superieure effecten ook alsmaar niet gevonden kunnen worden. Dat geldt voor weinig voorkomende ziektebeelden zoals 'somatisatiestoornis', maar ook voor frequent voorkomende ziektebeelden zoals 'dysthymie' en 'aanpassingstoornis'. Beslist niet iedere DSM-IV stoornis leent zich voor een gestandaardiseerde behandeling. In die gevallen waarin dat niet kan of nog niet gebeurd is, blijven traditionele, individuspecifieke behandelingen wenselijk en nodig. Daarmee groeit de overeenstemming dat protocollaire ESTs op indicatie of in combinatie met traditionele psychotherapeutische behandelingen kunnen worden toegepast (o.a. Davison 1998; Eifert e.a. 1997; Gaston \& Gagnon 1996; Heimberg 1998; Iwamasa \& Orsillo 1997; Kendall e.a. 1998; Schulte 1996; Schulte \& Eifert 2002). Beide behandelvormen bijten elkaar niet en kunnen binnen een behandelinstelling als behandelopties prima naast elkaar bestaan. In deze bijdrage willen wij opnieuw aan deze vreedzame co-existentie bijdragen. We gaan in op kritiek

1 Deze bijdrage betreft een ingekorte versie van: Keijsers, G.P.J., Verbraak, M.J.P.M., Ten Broeke, E., \& Korrelboom, K. (2009). Psychologische behandelingen volgens een protocol. In E. Ten Broeke, K. Korrelboom \& M. Verbraak (Red.), Praktijkboek geïntegreerde cognitieve gedragstherapie: Protocollaire behandelingen op maat (pp. 39-59). Bussum: Coutinho. 
van auteurs op protocollaire ESTs en op hun bezorgdheid over de veranderingen die ESTs met zich meebrengen. We bespreken voordelen, nadelen en vooroordelen bij de toepassing van ESTs en we eindigen met suggesties hoe ESTs in de zorgpraktijk zinnig kunnen worden toepassing.

Vooroordelen, voordelen, nadelen en adviezen bij de toepassing van protocollaire behandelingen In vergelijking met traditionele, individuspecifieke behandelingen beschikken protocollaire ESTs over een aantal opvallende eigenschappen. Ze zijn bewezen effectief en over de verwachte duur en kans op verbetering kan vooraf al betrouwbare informatie gegeven worden. Verder zijn de behandelingen gefocust, compleet, transparant en goed in te trainen. Tegenover deze gunstige eigenschappen staan ook mogelijk ongunstige zaken. Men kan zich afvragen of therapeuten en patiënten door het behandelprotocol niet in een keurslijf gedwongen worden, of een protocollaire behandeling wel voldoende gebruik maakt van de deskundigheid van de therapeut en of algemene therapeutische vaardigheden in een protocollaire behandeling niet te weinig aan bod komen. Hieronder gaan we op deze punten in. Daarbij staat ons steeds een zinnig gebruik van protocollaire ESTs voor ogen

\section{Bewezen effectief}

Protocollaire behandelingen hebben meestal een duidelijk indicatiegebied. In de regel is dat een primaire As-I diagnose. Voor die doelgroep is de desbetreffende behandeling goed getest. Als de diagnose kan worden gesteld, mag bij correcte uitvoering van de behandeling een resultaat verwacht worden dat in de lijn ligt van het verrichtte onderzoek. Critici opperen nogal eens dat dat onzin is. Bevindingen uit onderzoek gaan immers over grote groepen patiënten. De bevindingen zijn een gemiddelde. Gemiddelde patiënten bestaan echter niet. Onderzoeksbevindingen zouden daarom niks zeggen over het behandeleffect voor meneer of mevrouw $\mathrm{X}$ die zich zojuist voor behandeling aangemeld heeft.

Die redenering is onjuist. Het groepsgemiddelde vormt juist de sterkste schatter van het behandelresultaat bij iedere nieuwe patiënt. Dat is precies wat het gemiddelde betekent. Zolang andere betrouwbare schatters ontbreken - en dat is de situatie binnen psychotherapie - is het gemiddelde behandelresultaat met een bepaalde behandeling voor een bepaalde stoornis de beste voorspeller voor het resultaat van een willekeurig andere patiënt die met dezelfde behandeling voor dezelfde stoornis behandeld wordt. Het gebeurt jammer genoeg nogal eens dat behandelaars dat niet geloven.

Een ander veel gehoord argument tegen protocollen is dat de bevindingen uit gerandomiseerd gecontroleerd onderzoek (Randomised Controled Trials: RCTs) niet generaliseerbaar zijn naar de dagelijkse behandelpraktijk. In de praktijk van alle dag komen patiënten met een eenduidige stoornis zonder comorbiditeit weinig voor. De patiëntenpopulatie waarmee in de praktijk gewerkt wordt zou meer heterogeen, complexer en zieker zijn dan de patiëntenpopulatie waarover onderzoeksbe- vindingen werden gerapporteerd. Verder zijn onderzoekscentra vaker gespecialiseerd in de behandeling van bepaalde stoornissen. De therapeuten worden gesuperviseerd door experts. Behandelgegevens worden bijgehouden en er worden controles uitgevoerd. Een dergelijke onderzoekscontext ontbreekt in de routine behandelpraktijk. Het is dus nog maar de vraag of protocollaire behandelingen in de praktijk tot dezelfde, gunstige resultaten gaan leiden als bij RCTs.

Tegen deze argumenten valt het nodige in te brengen. Het is juist dat in RCTs inclusie- en exclusiecriteria gehanteerd worden. Het inclusiecriteriumvoorstoornisspecifiekbehandeleffectonderzoek is in de regel de primaire DSM-IV diagnose (Chambless, 1996). Hierop is de behandeling immers toegesneden. Exclusiecriteria zijn in de regel ernstige psychopathologie zoals een psychotische stoornis, organisch syndroom of middelenafhankelijkheid. Onderzoekers kunnen zich om praktische redenen echter zelden veroorloven om patiënten met additionele DSM-IV as-I of as-II stoornissen te excluderen. Het zou vele jaren duren voordat een onderzoeker bijvoorbeeld voldoende 'pure' anorexianervosapatiënten heeft voor onderzoek (Barlow e.a. 1999; Chambless 1996; Heimberg 1998). Een primaire diagnose als inclusiecriterium betekent meestal dat de diagnose waarom het gaat, gesteld moet kunnen worden en dat deze stoornis volgens de intaker of onderzoeker en patiënt ook als eerste de aandacht verdient in de behandeling. Dat ook een tweede of een derde, mogelijk ernstige stoornis aanwezig is, leidt meestal niet tot uitsluiting van het onderzoek als de behandeling op dit moment maar op de primaire diagnose kan worden ingezet. Uiteraard zijn er onderzoekstrials waarin de patiëntpopulatie relatief milde klachten had. Daar staat tegenover dat in onderzoekstrials even zo vaak ernstig zieke patiënten protocollair behandeld werden. Monosymptomatische patiënten met milde klachten zijn zeldzaam in de dagelijkse praktijk. Directe vergelijking van gegevens van patiënten die wel en niet aan onderzoekstrials hadden deelgenomen, maakt duidelijk dat de ernst van de klachten en het voorkomen van dubbeldiagnoses niet anders is. Sterker nog, vaker dan patiënten met zware klachten, werden juist patiënten met lichte klachten uit onderzoekstrials uitgesloten (Stirman e.a. 2003; Stirman e.a. 2005).

Wat het belang van de onderzoekscontext betreft, kan alleen onderzoek uitwijzen of succesvolle protocollaire behandelingen uit onderzoekstrials ook succesvol kunnen worden toegepast in praktijkcentra. In elf studies is dat inmiddels gebeurd. Het betreft ondermeer protocollaire behandelingen voor de obsessieve-compulsieve stoornis, depressie, boulimia nervosa en paniekstoornis. Toepassing van ESTs in reguliere praktijkinstellingen leidt tot vergelijkbare behandelresultaten als die van de ESTs in onderzoekstrials (o.a. Addis 2002; Addis \& Cardemil 2005; Franklin \& DeRubeis 2005; Weersing \& Weisz 2002).

Dit alles betekent voor de toepassingspraktijk dat een behandelaar over nogal goede argumenten moet beschikken om patiënten die voldoen aan het indicatiegebied van een EST, zo'n behandeling toch te onthouden. De vraag is eigenlijk eerder waarom een therapeut dat zou willen. Een mogelijke reden is het geloof van de therapeut in zijn of haar mogelijkheden - en die van de patiënt 
- om een goed behandelresultaat te bereiken met een ongeteste behandelmethode. Dat laatste komt zondermeer voor. Er bestaan beslist goede en bijzonder werkzame maar nog ongeteste behandelmethoden. Het probleem is echter de argumentatie daartoe. Om welke reden zou men de voorkeur geven aan een behandelmethode waarvan de werkzaamheid onbekend is boven een goed onderzochte en werkzame behandelmethode? Is in dat geval de patiënt van zo'n keuze ook goed op de hoogte gesteld? Een tweede, mogelijke reden is dat de therapeut zich in de EST niet goed kan vinden, met een dergelijke methode eigenlijk onvoldoende bekend is, of deze te arbeidsintensief vindt. Immers, protocollaire ESTs vergen voorbereiding van therapeuten. Men moet zich het protocol eigen maken en bepaalde zaken gedurende de sessies in de gaten houden. Sommige onderwerpen moeten met grote zorgvuldigheid besproken worden, bij andere onderwerpen dient het gesprek kort gehouden te worden. Is dit het geval, dan is het het verstandigst dat de therapeut de patiënt verwijst naar een collega die met de betreffende protocollaire behandeling meer affiniteit heeft (zie ook Addis \& Krasnow 2000).

\section{Goede informatie over de behandelresultaten}

Wanneer een patiënt voldoet aan het indicatiegebied van een protocollaire EST dan kan de patiënt bij afsluiting van de diagnostische fase belangrijke informatie geboden worden die de patiënt helpt bij het maken van een keuze. Er is betrouwbare informatie beschikbaar over de prognose, de duur van de behandeling, de noodzakelijke investeringen en de kans op dropout. Vaak is er ook goede informatie over de lange termijn resultaten en over de resultaten van alternatieve behandelmethoden. In RCTs werden de resultaten van meerdere behandelingen immers rechtstreeks met elkaar vergeleken. Voorwaarde is wel dat de diagnosticus of therapeut over deze kennis beschikt. Beschikbare, empirisch ondersteunde behandelingen worden lang niet binnen alle behandelinstellingen gebruikt. Bij veel hulpverleners ontbreekt nog steeds kennis, ervaring en soms ook vertrouwen in een dergelijke manier van werken. Bij een grote, representatieve steekproef onder geregistreerde, in de klinische praktijk werkzame psychologen in de Verenigde Staten had minder dan 50 procent een helder idee over wat protocollaire behandelingen waren. Achtenvijftig procent had zelden of nooit een protocollaire behandeling gebruikt en 31 procent soms. Slechts 12 procent paste meerdere protocollaire behandelingen toe (Addis \& Krasnow 2000). Met betrekking tot opleidingen bleek dat in minder dan de helft van de door de American Psychological Association geaccrediteerde doctorale en postdoctorale klinische psychologieopleidingen ESTs gedoceerd werden, ondanks het feit dat het bij ESTs om bewezen effectieve behandelingen gaat (Crits-Christoph e.a. 1995). Wij hebben de indruk dat voor opleidingen in Nederland de situatie eveneens verbeterd kan worden. Als er ESTs zijn voor een bepaalde psychische stoornis, dan moet patiënten daarvan op de hoogte worden gesteld en dan hebben patiënten recht op zo'n behandeling. Evenals het voor therapeuten geldt, geldt het ook voor opleidingen die studenten voorbereiden op beroepen in de gezondheidszorg: men moet wel over zeer bijzondere argumenten beschikken om studenten niet in empirisch ondersteunde, protocollaire behandelingen op te leiden.

\section{Gefocuste en gedetailleerde karakter}

Een volgende eigenschap van protocollaire ESTs is het gefocuste en gedetailleerde karakter. Het behandelprotocol biedt interventies die specifiek zijn gemaakt voor een bepaalde stoornis. Voor patiënten met een paniekstoornis is cognitieve therapie bijvoorbeeld specifiek toegespitst op catastrofale misinterpretaties van lichamelijke angstsensaties en exposure-opdrachten bevatten oefeningen met het opwekken van lichamelijke sensaties (bijvoorbeeld hyperventileren, draaierigheid) die lijken op sensaties die ook bij paniekaanvallen voorkomen. Hetzelfde geldt voor behandelrationale, voorbeelden, informatiemateriaal en meetinstrumenten: ook deze zijn specifiek gemaakt voor patiënten met de betreffende stoornis. Verder zijn de behandelprotocollen vaak gedetailleerd. Dit gedetailleerde karakter vergroot de transparantie van de behandelingen en maakt dat therapeuten goed in de behandelingen te trainen en te superviseren zijn. Dit alles werpt een aantal vragen op. Hoe gewenst is zo'n focus eigenlijk? Betekent het dat onder geen beding van het protocol mag worden afgeweken? Worden therapeut en patiënt dan bovendien niet in een te eng keurslijf gedwongen?

Het is heel waarschijnlijk dat juist de stoornisspecifieke focus van ESTs - en daaraan toegevoegd, het protocol dat de therapeut bij de les houdt zodat de behandeling zich stap voor stap over de weken heen ontwikkelt - deze behandelingen zo effectief maakt (Castonguay \& Beutler, 2006; Keijsers e.a. 2004). Dat houdt in dat de beschreven behandelmethoden in zo'n protocol ook echt uitgevoerd moeten worden. Van de andere kant is moeilijk te bedenken waarom protocollaire behandelingen ook in de dagelijkse praktijk zo strikt en naar de letter uitgevoerd moeten worden als de uitvoering ervan in het kader van een RCT vereist. In dat laatste geval moet de onderzoeker immers kunnen waarborgen dat tijdens de behandeling precies dat werd gedaan wat in het protocol beschreven stond. Dat is niet zo wanneer bij eigen patiënten en binnen reguliere behandeling besloten wordt tot een protocollaire behandeling. Dan is er feitelijk maar één reden te bedenken waarom een behandelprotocol naar de letter zou moeten worden opgevolgd. Die reden is dat volledige handhaving van het oorspronkelijke protocol de meest zekere weg is om ook bij eigen patiënten dezelfde resultaten te bereiken als uit het onderzoek naar voren kwamen. Voor de details van de behandeling is het de vraag of dat een afdoende reden is. Van geen enkele EST werd of kan worden onderzocht of het uitmaakt dat bijvoorbeeld met exposure-opdrachten precies in sessie 6 begonnen wordt, of dat de toepassing van assertiviteitsoefeningen niet meer dan drie sessies mogen vergen. Mogelijke effectverschillen op een dergelijk gedetailleerd niveau zijn alleen wetenschappelijk te onderzoeken als men over honderden patiënten kan beschikken. De kans is reëel dat eventuele gevonden verschillen dan klein en triviaal zijn en niet opwegen tegen praktische redenen om de protocollaire behandeling aan individuele omstandigheden aan te passen. 
In de reguliere behandelpraktijk kan het protocol daarom beter als een prototypisch voorbeeld worden beschouwd: zo moet het in grote lijnen, kleine variaties kunnen voorkomen. Het was achteraf gezien misschien beter geweest om niet van 'protocollen' te spreken toen deze voor de reguliere praktijk beschikbaar kwamen. 'Gids' of 'raamwerk' waren mogelijk betere benaming geweest (Addis \& Cardemil 2005). Het is nodig dat de therapeut het protocol kent, begrijpt en naar de geest van het protocol de behandeling toepast. Dat betekent dat de componenten en therapeutische procedures uit de behandeling uitgevoerd worden en dat daaraan niet zomaar geheel andere procedures worden toegevoegd. De interventies, huiswerkopdrachten en adviezen moeten passen binnen de behandellijn van het protocol. Als daarvoor wordt gezorgd, is het vervolgens zinnig om protocollaire ESTs in de dagelijkse behandelpraktijk flexibel en naar de geest van het protocol uit te voeren. De behandeling wordt 'op maat gesneden' en aan de individuele patiënt en zijn of haar omstandigheden aangepast (Chambless 1996; Crits-Christoph 1998; Davison 1998; Eifert e.a. 1997; Iwamasa \& Orsillo 1997; Kendall e.a. 1998; Wilson 1996).

Verder is het naar onze ervaring ook niet zo dat therapeuten die met protocollaire behandelingen werken, deze behandelingen als een eng keurslijf ervaren, zelfs niet als behandelingen worden uitgevoerd in het kader van onderzoek. De schaarse onderzoeksbevindingen op dit punt lijken evenmin op een sterke beperking van therapeutische mogelijkheden te duiden. Hardy e.a. (1998) vonden dat therapeuten bij het uitvoeren van protocollaire behandelingen geen moeite hadden om zich toch aan de interpersoonlijke stijl van hun cliënten aan te passen. Kendall en Chu (2000) rapporteerden bij de verplichte toepassing van een protocollaire behandeling bij kinderen met angstklachten dat de therapeuten vonden dat ze de behandelingen toch redelijk flexibel hadden kunnen uitvoeren. Op een 7-puntsschaal van 1 'in het geheel niet flexibel' tot 7 'geheel flexibel' scoorden de therapeuten gemiddeld een 4. Bijzonder was bovendien dat er geen samenhang was tussen de flexibiliteitscore en het therapieresultaat. Iets dergelijks deed zich in de studie van Keijsers e.a. (submitted) ook voor. Studenten met spanningsklachten kregen een training in ontspanning die of op rigide wijze (alle instructies lagen vast, therapeuten lazen zinnen letterlijk op) of op flexibele wijze (bespreken van individuele klachten, persoonlijke interactie, aanpassing van opdrachten aan de wensen van de student) werd aangeboden. Er was geen verschil in behandelresultaat tussen de condities. De uitvoering van huiswerkopdrachten was zelf iets beter in de rigide behandelconditie. Deze bevindingen wijzen er op dat inflexibiliteit mogelijk niet alleen maar negatieve effecten heeft op het behandelresultaat. Mogelijk is een behandeling vooral gediend met eenduidige instructies.

Het is niet zo heel vreemd dat protocollaire behandelingen niet als bijzonder beknellend ervaren worden. Het protocol maakt veel gebruik van taxaties en observaties van de therapeut en van informatie van de patiënt om de verdere voortgang van een behandeling te bepalen. Tot de taxaties en observaties behoren bijvoorbeeld inschattingen over de bereidheid van patiënten om met bepaalde onderdelen van de behandeling aan de slag te gaan, over het tempo van gesprekken, de mate van sturing die de therapeut daarbij het best kan bieden, de ernst van de klachten, enzovoort. Bij informatie van patiënten gaat het bijvoorbeeld om specificaties van situaties waarin klachten zich voordoen, om beschrijvingen van gedrag, gedachten, gevoelens, ervaringen met het huiswerk van de vorige sessie, en zo voort. Ook al ligt de keuze voor een of meerdere therapeutische technieken in het protocol vaak vast, de daadwerkelijke invulling ervan moet, afgestemd op de patiënt, door de therapeut en de patiënt uitgevoerd worden. Het verschil met traditionele, individuspecifieke behandeling is veel minder groot dan het lijkt. Kortom, een behandelprotocol is minder een keurslijf dan men vaak aanneemt. Het protocol biedt wel degelijk ruimte voor het maken van keuze en flexibele interactie. Daarnaast kunnen de richtlijnen de behandeling ook aantrekkelijk maken door de therapeut en de patiënt duidelijkheid, structuur en een houvast te bieden.

\section{Beoordelingsvermogen, deskundigheid en competentie van de therapeut}

Protocollaire behandelingen maken wel degelijk gebruik van het beoordelingsvermogen en de deskundigheid van de therapeut. Dat de lijn van de behandeling door het protocol wordt vastgelegd, is waarschijnlijk niet slecht (Addis \& Cardemil 2005; Castonguay \& Beutler 2006). Diagnostiek, taxaties, behandelindicaties en keuzes bij de uitvoering van behandelingen zijn immers buitengewoon complex en onderzoeksresultaten bieden een weinig vreugdevol beeld over de accuratesse van het klinische oordeel (o.a. Garb \& Boyle 2003; Wilson 1996). Emmelkamp (1993) vergeleek bijvoorbeeld functieanalyses en behandelplannen opgesteld door ervaren therapeuten met die van het behandelteam, opgesteld aan de hand van bandopnames van de gesprekken met de therapeut. De overeenstemming was matig. Evenmin bieden onderzoeksgegevens consistente ondersteuning voor de aanname dat het aantal ervaringsjaren van therapeuten samenhangt met betere behandelresultaten (Christensen \& Jacobson 1994; Garb \& Boyle 2003; Schulte e.a. 1992; Smith e.a. 1980; Wilson 1996). Diagnostici en therapeuten ontkomen bij hun beoordelingen niet aan axioma's, ongefundeerde aannames en willekeur. Wilson (1996) en Chambless en Crits-Christoph (2005) oordelen dan ook dat empirische validatie door de lijn van empirisch ondersteunde behandeling te volgen, de voorkeur verdient boven het varen op beoordelingen van individuele therapeuten bij het opstellen van behandelingen.

Gaat het daarentegen niet zozeer om de ervaring van de therapeut, maar om de competentie van de therapeut om bepaalde behandelingen uit te voeren, dan zijn behandelprotocollen bij uitstek geschikt om therapeuten te trainen in de specifieke vaardigheden die voor de behandeling nodig zijn (o.a. Lambert \& Bergin 1994; Moras 1993; Rounsaville e.a., 1988). Hier dienen twee punten te worden benadrukt. Het eerste punt is dat training in een protocollaire EST ook echt nodig is. ESTs zijn gebruikersvriendelijk, gestructureerd en vaak compleet omdat ze voorzien zijn van informatiefolders, huiswerkformulieren, registratieopdrachten en meetinstrumenten. 
Zorginstellingen kunnen bijgevolg wel eens de neiging hebben om een patiënt waarbij protocollaire behandeling aangewezen is, naar de 'jongste bediende' door te schuiven zonder deze verder in de protocollaire behandeling te trainen. In de RCTs waarin de behandelingen werden getest, werd echter altijd getraind. De therapeuten werden tot experts in de behandeling opgeleid. De training hoort bij de toepassing van de protocollaire behandeling. Ook in de dagelijkse praktijk is zo'n training nodig. Men oefent met elkaar zodat de therapeuten de technieken doorgronden, de woorden en beelden vinden om zaken aan de patiënt uit te leggen, ervaring krijgen met het geven van de huiswerkopdrachten, een goed beeld krijgen van de verwachtte effecten van dergelijke opdrachten, enzovoort. Protocollaire behandelingen wijken daarin niet af van individugerichte behandelingen. Training is echt nodig om ze effectief toe te kunnen toepassen (Craighead \& Craighead 1998; Crits-Christoph 1996; Davison 1998) en zorginstellingen dienen te voorzien in de middelen daartoe.

Het tweede punt dat de aandacht verdient met betrekking tot opleiding is dat niet alleen training in ESTs nodig is, maar ook scholing in algemene therapeutische vaardigheden (o.a. Davison 1998; Eifert e.a. 1997; Iwamasa \& Orsillo 1997; Schulte 1996). Dat een behandelprotocol een therapeut stap voor stap instrueert bij de uitvoering van een behandeling mag beslist niet verward worden met het idee dat de therapeut dus ook de patiënt instrueert in de behandeling. Protocollaire behandelingen kunnen gemakkelijk het idee versterken dat de succesvolle behandelprocedures netjes in het protocol beschreven staan en enkel nog aan de patiënt behoeven te worden voorgelegd. Zo is dat niet. Een belangrijk deel van het werk van therapeuten bestaat er juist uit de patiënten voor behandelprocedures te motiveren en hen in staat te stellen van deze procedures te profiteren. Het zijn immers de patiënten zelf die met behulp van deze procedures verandering in hun eigen beleving en gedrag moeten gaan bewerkstelligen. Aansluiting, motivering en zorgvuldige begeleiding van de procedures is daarbij essentieel (Keijsers e.a. 2007). Veel behandelprotocollen besteden daar dan ook zorgvuldig aandacht aan.

\section{Protocollen als de norm}

Een laatste punt dient ook nog aan de orde te worden gesteld. Het succes van protocollaire ESTs kan ertoe leiden dat zorginstellingen ESTs als de norm gaan beschouwen en traditionele, individuspecifieke behandelingen als de uitzondering. Dat geldt ook voor de betalende instanties, de verzekeraars. De beleidslijn wordt dan dat bij elke patiënt een kortdurende behandeling toegepast behoort te worden volgens een vooraf vastgesteld behandeltraject waarvan alleen in uitzondering mag worden afgeweken. De therapeuten worden geacht daartoe in staat te zijn en na een sessie of twaalf een aardige vooruitgang geboekt te hebben.

Een dergelijke verwachting mag, mits met enige soepelheid betracht, reëel zijn voor stoornissen waarvoor ESTs bestaan, zij is dat beslist niet voor stoornissen waar dat (nog) niet het geval is. Het is dan zelfs de vraag in hoeverre het vaststellen van zo'n stoornis ons verder helpt bij de behandeling van de betreffende patiënt. Casusconceptualisatie is dan waarschijnlijk behulpzamer. Voor deze patiënten zal psychologische hulpverlening inhouden dat een individuspecifieke behandeling wordt ingezet. Die behandeling kan onverwacht kort of onverwacht lang duren en er kunnen meerdere koerswijzigingen worden ingezet waarbij meerdere behandelvormen, bijvoorbeeld combinaties met medicamenteuze behandeling, uitgetest gaan worden, of waarbij de partner of het gezin bij de behandeling betrokken wordt. Therapeuten moeten hierin de ruimte krijgen en niet door strenge beleidslijnen worden beknot. Ook de verwachtingen ten aanzien van het resultaat van individuspecifieke behandelingen moeten reëel blijven. Beleidslijnen zijn nodig, maar als bij bepaalde patiënten onduidelijk is wat de best te volgen behandellijn is, dan moet de therapeut de vrijheid hebben om dat uit te zoeken.

\section{Besluit}

Protocollaire psychologische ESTs hebben hun weg naar de dagelijkse zorgpraktijk gevonden. Het besef groeit dat de toepassing van ESTs en van individuspecifieke behandelingen als behandeloptie binnen een zorginstelling op zinnige wijze naast elkaar kunnen bestaan. In deze bijdrage boden we een overzicht van vooroordelen, voordelen en nadelen van protocollaire behandelingen en werden adviezen gegeven voor het gebruik ervan in de behandelpraktijk. Beknopt samengevat luiden deze adviezen als volgt:

- ESTs dienen te zijn opgenomen in het cursorisch programma en trainingenonderwijs van alle onderwijsinstellingen die studenten opleiden tot hulpverlening bij patiënten met psychische klachten.

- Als patiënten voldoen aan het indicatiegebied van een EST dan dienen patiënten hiervan op de hoogte te worden gesteld en dient zo'n behandeling te worden aangeboden. Als de instelling of de behandelend therapeut daartoe niet in staat of bereid is, dan dient dat met de patiënt te worden besproken en moet doorverwijzing naar een plek waarop deze behandeling wel geboden kan worden tot de opties behoren.

- Als voor patiënten geen ESTs voorhanden zijn, dan is traditionele, individuspecifieke behandeling wenselijk en nodig. Therapeuten worden dan als experts ingezet om uit te zoeken hoe de patiënt verder te helpen is. Hierin moeten therapeuten de ruimte krijgen en niet door ongeschikte beleidslijnen worden beknot.

- Protocollaire ESTs dienen in de dagelijkse praktijk niet naar de letter maar naar de geest van het protocol te worden toegepast. De specifieke invulling en duur van de behandeling wordt aangepast aan de patiënt en zijn of haar omstandigheden.

- Het is onjuist om patiënten die middels een protocollaire EST behandeld gaan worden aan de 'de jongste bediende' toe te bedelen met de opmerking dat het protocol zichzelf wel wijst. Therapeuten dienen te worden getraind in de toepassing van een protocollaire behandeling. Als de therapeut relatief onervaren is, dan is bovendien een goede training in algemene therapeutische vaardigheden nodig. 


\section{Literatuu}

- Addis, M.E. (2002). Implicit and untested assumptions about the role of psychotherapy treatment manuals in evidence-based mental health practice. Clinical Psychology: Science and Practice, 9, 421-424.

- Addis, M.E., \& Cardemil, E.V. (2005). Does manualization improve therapy outcomes? Psychotherapy manuals can improve outcomes. En dialogue: convergence and contention. In J.C. Norcross, L.E. Beutler, \& R.F. Levant (Red.), Evidencebased practices in mental health: Debate and dialogue on the fundamental questions (pp. 131-140 en 149-153). Washington, D.C.: American Psychological Association.

- Addis, M.E., \& Krasnow, A.D. (2000). A national survey of practicing psychologists' attitudes toward psychotherapy treatment manuals. Journal of Consulting and Clinical Psychology, 68, 331-339.

- Barlow, D.H., (2007). Psychotherapy and psychological treatments: The future Clinical Psychology: Science and Practice, 13, 216-220.

- Barlow, D.H., Levitt, J.T., \& Bufka, L.F. (1999). The dissemination of empirically supported treatments: A view to the future. Behaviour Research and Therapy, 37 S147-S162.

- Castonguay, L.G, \& Beutler, L.E. (2006). Common and unique principles of therapeutic change: What do we know and what do we need to know? In: L.G. Castonguay \& L.E. Beutler (Red.), Principles of therapeutic change that work (pp. 353-369). Oxford: Oxford University Press.

- Chambless, D.L. (1996). In defence of dissemination of empirically supported psychological interventions. Clinical Psychology: Science and Practice, 3, 230-235.

- Chambless, D.L., \& Crits-Christoph, P. (2005). What should be validated? The treatment method. In: J.C. Norcross, L.E. Beutler, \& R.F. Levant (red), Evidencebased practices in mental health: Debate and dialogue on the fundamental questions (pp. 191-200). Washington, D.C.: American Psychological Association.

- Chambless, D.L., \& Ollendick, T.H. (2001). Empirically supported psychological interventions: Controversies and evidence. Annual Review of Psychology, 52, 685-716

- Christensen, A., \& Jacobson, N.S. (1994). Who (or what) can do psychotherapy: The status and challenge of nonprofessional therapies. Psychological Science, 5, 8-14.

- Craighead, W.E., \& Craighead, L.W. (1998). Manual-based treatments: Suggestions for improving their clinical utility and acceptability. Clinical Psychology: Science and Practice, 5, 403-407.

- Crits-Christoph, P. (1996). The dissemination of efficacious psychological treatments. Clinical Psychology: Science and Practice, 3, 260-263.

- Crits-Christoph, P. (1998). Training in empirically validated treatments: The division 12 apa task force recommendations. In: K.S. Dobson \& K.D. Craig (Red.), Empirically supported therapies: Best practice in professional psychology (pp. 3-25). Thousand Oaks: Sage Publications.

- Crits-Christoph, P., Frank, E., Chambless, D.L. e.a. (1995). Training in empirically validated treatments: What are clinical psychology students learning? Professional Psychology: Research and Practice, 26, 514-522.

- Davison, G.C. (1998). Being bolder with the boulder model: The challenge of education and training in empirically supported treatments. Journal of Consulting and Clinical Psychology, 66, 163-167.

- DeRubeis, R.I., \& Crits-Christoph, P. (1998). Empirically supported individual and group psychological treatments for adult mental disorders. Journal of Consulting and Clinical Psychology, 66, 37-52.

- Eifert, G.H., Schulte, D., Zvolensky, M.J. e.a. (1997). Manualized behavior therapy: Merits and challenges. Behavior Therapy, 28, 499-509.

- Emmelkamp, P.M.G. (1993). Empirisch gehalte van de functie-analyse. Gedragstherapie, 26, 211-216.

- Franklin, M.E., \& DeRubeis, R.J. (2005). Efficious laboratotry-validated treatments are generally transportable to clinical practice. In J.C. Norcross, L.E. Beutler \& R.F. Levant (Eds), Evidence-based practices in mental health: Debate and dialogue on the fundamental questions (pp. 375-383, 393-395). Washington, D.C.: American Psychological Association.

- Garb, H.N., \& Boyle, P.A. (2003). Understanding why some clinicians use pseudoscientific methods: Findings from research on clinical judgement. In S.O. Lilieneld, S.J. Lynn, \& J.M. Lohr (Red.), Science and pseudoscience in clinical psychology (pp. 17-38). New York: Guilford Press.

- Gaston, L., \& Gagnon, R. (1996). The role of process research in manual development. Clinical Psychology: Science and Practice, 3, 13-24.

- Hardy, G.E., Stiles, W.B., Barkham, M. e.a. (1998). Therapist responsiveness to client interpersonal styles during time-limited treatments for depression. Journal of Consulting and Clinical Psychology, 66, 304-312.
- Heimberg, R.G. (1998). Manual-based treatment: An essential ingredient of clinical practice in the 21st century. Clinical Psychology: Science and Practice, 5, 387-390.

- Iwamasa, G.Y., \& Orsillo, S.M. (1997). Individualizing treatment manuals as a challenge for the next generation. Behavior Therapy, 28, 511-515.

- Keijsers, G.P.J., Minnen, A. van, \& Hoogduin, C.A.L. (2004). Protocollaire behandelingen in de ambulante GGZ. In G.P.J. Keijsers, A. Van Minnen \& C.A.L. Hoogduin (Red.), Protocollaire behandelingen in de ambulante geestelijke gezondheidszorg. Deel 1 (2e druk) (pp. 1-31). Houten: Bohn Stafleu Van Loghum.

- Keijsers, G.P.J., Vissers, W., Eberson, J., Ermers, A.,\& Hutschemaekers, G. (sumitted). Manual-based treatment put at the test: Comparing outcomes of rigidly or flexibly delivered treatments in a treatment-analogous experiment.

- Keijsers, G.P.J., Vossen, C.JC., \& Keijsers, L.H.A. (2007). Motiveringsstrategieën in de ambulante psychotherapie. Houten: Bohn Stafleu Van Loghum.

- Kendall, P. C. Chu, B., Gifford, A. e.a. (1998). Breathing life into a manual. Cognitive and Behavioral Practice, 5, 177-198.

- Kendall, P.C. \& Chu, B.C. (2000). Retrospective self-reports of therapist flexibility in a manual-based treatment for youths with anxiety disorders. Journal of Clinical Child Psychology, 29, 209-220.

- Lambert, M.J., \& Bergin, A.E. (1994). The effectiveness of psychotherapy. In: A.E. Bergin \& S.L. Garfield (Red.), Handbook of psychotherapy and behavior change (4e druk, pp. 143-189). New York: Wiley.

- Moras, K. (1993). The use of treatment manuals to train psychotherapists: Observations and recommendations. Psychotherapy, 30, 581-586.

- Roth A., \& Fonagy, P. (2005). What works for whom? A critical review of psychotherapy research (2nd ed.). London: Guilford Press.

- Rounsaville, B.J., O’Malley, S., Foley, S., \& Weissman, M.M. (1988). Role of manual-guided training in the conduct and efficacy of interpersonal psychotherapy. Journal of Consulting and Clinical Psychology, 56, 681-688.

- Schulte, D. (1996). Tailor-made and standardized therapy: Complementary tasks in behavior therapy a contrarian view. Journal of Behavior Therapy and Experimental Psychiatry, 27, 119-126.

- Schulte, D., \& Eifert, G.H. (2002). What to do when manuals fail? The dual model of psychotherapy. Clinical Psychology: Science and Practice, 9, 312-328.

- Schulte, D., Künzel, R., Pepping, G. e.a. (1992). Tailor-made versus standardized therapy of phobic patients. Advances in Behaviour Research and Therapy 14, 67-92.

- Smith, M.L., Glass, G.V., \& Miller, T.I. (1980). The benefits of psychotherapy. Baltimore: John Hopkins University Press.

- Stirman, S.W., DeRubeis, R.J., Crits-Christoph, P. e.a. (2003). Are samples in randomized controlled trials of psychotherapy representative of community outpatients? A new methodology and initial findings. Journal of Consulting and Clinical Psychology, 71, 963-972.

- Stirman, S.W., DeRubeis, R.J., Crits-Christoph, P. e.a. (2005). Can the randomized controlled trial literature generalize to non-randomized patients? Journal of Consulting and Clinical Psychology, 73, 127-135.

- Weersing, V.R., \& Weisz, J.R. (2002). Community clinic treatment of depressed youth: Benchmarking usual care against CBT clinical trials. Journal of Consulting and Clinical Psychology, 70, 299-310.

- Wilson, G.T. (1996). Manual-based treatments: The clinical application of research findings. Behaviour, Research and Therapy, 34, 295-314.

- Correspondentie

Dr. Ger P.J. Keijsers, klinisch psycholoog, psychotherapeut Universitair Hoofddocent, BSI Radboud Universiteit Nijmegen, Postbus 9104, 6500 HE Nijmegen

g.keijsers@psych.ru.nl

Tel. +31-24-361-5626

Fax. $+31-24-361-5594$ 